\title{
Algumas reflexões acerca da categoria da alienação no marxismo francês entre o final da segunda guerra e os anos 60
}

Mônica Hallak Martins da Costa ${ }^{1}$

Resumo: A década que se estende entre finais dos anos 1950 e dos anos 1960 pode, certamente, ser considerada como o período mais profícuo do marxismo no século XX. A fertilidade desse movimento intelectual, na França, não se restringiu aos estudiosos de Marx, mas ampliou a interlocução do marxismo com outros autores e promoveu uma abertura que tornou possível o debate de temas, antes negligenciados pela abordagem oficial, como é o caso da reflexão acerca da alienação. Nesta comunicação, recupera-se parte da produção de três autores - Henri Lefebvre, André Gorz e Lucien Sève - que trataram do tema e se preocuparam, tanto com os rumos do chamado "socialismo realmente existente", quanto com o resgate dos escritos de Marx em sua integridade; ou seja, despidos de preconceitos do período stalinista, que deixaram de lado qualquer reflexão acerca do papel dos indivíduos na história e do lugar da subjetividade nos processos humanos. Não se pode esquecer, na presente análise, que o Partido Comunista Francês (PCF) foi uma das organizações que mais fielmente seguiu a linha oficial do PC URSS, o que intensifica o interesse pelas abordagens que se propuseram a questioná-lo.

Palavras-chave: alienação, marxismo francês, indivíduo.

Abstract: The time raging from the end of the 1950's and the 1960's can certainly be seen as the most beneficial for Marxism in the 20th century. The fertility of this intellectual practice, in France, was not restricted to those who studied Marx, as it also enhanced the dialog between Marxists and other authors, and promoted the debate of themes once neglected by official approaches. "Alienation" is one of such themes.

1 Professora da Escola de Serviço Social da PUC Minas. Correio eletrônico: monicahallak@uol.com.br cadernos cemarx, $\mathrm{n}^{\circ} 5-2009 \quad 77$ 
This communication discusses the production of three authors who have studied the theme of alienation: Henri Lefebvre, André Gorz and Lucien Sève, who have always been concerned with the so-called "real socialism", as well as with recovering Marx's writings in their entirety. Lefebvre, Gorz and Sève let go of certain preconceived ideas from the Stalinist era, ideas that have ignored any and every kind of reflection upon the role of individuals in history, and the place of subjectivity in human processes. It's important to state that the French Communist Party (PCF) was one of the organizations which most faithfully followed the ideas of the Soviet Union Communist Party, a fact which thus generates more interest for approaches that question such parties' lines of thinking.

Keywords: alienation, French Marxism, individuals.

No imediato pós-segunda guerra, Lefebvre redige o primeiro volume de Crítica da Vida Cotidiana (1958). Em 1936 já havia apresentado ao público o livro A consciência mistificada (1979), escrito com Norbert Guterman, cuja publicação rejeitada pelo comunismo "soviético" sendo, mais tarde, proscrito e queimado pelos nazistas. Nos dois trabalhos, como o próprio Lefebvre admite no prefácio de 1958 à segunda edição da primeira parte de Crítica, a alienação - analisada nos termos de Marx - surge como preocupação central. Não é por acaso que esses dois textos aparecem justamente após momentos de grande mobilização da esquerda francesa, seguidos de atitudes cautelosas das lideranças frente à possibilidade revolucionária² Com efeito, o Partido Comunista Francês (PCF) assumiu sem maiores questionamentos a política da URSS no período entre guerras e ao final do segundo conflito mundial $\operatorname{armado}^{3}$. A estratégia de Moscou, como se sabe, consistia na "subordinação da

\footnotetext{
2 Claudín (1986) caracteriza o período pós-guerra na França como "revolução frustrada".

$3 \mathrm{O}$ debate em torno da categoria da alienação estava relacionado a inúmeras outras situações históricas, no cenário francês e internacional, que não serão tratadas aqui, como, por exemplo, a cisão sino-soviética, a revolução cubana, a revolução chinesa e a explosão do maio de 1968. Como se trata de uma análise categorial, a pesquisa histórica foi introduzida somente na medida em que esclarece minimamente os termos nos quais o debate se instalou. Não se pretende, portanto, com este artigo, levantar ou desenvolver hipóteses acerca da inserção dos autores em questões específicas, mas tão somente evidenciar o retorno aos trabalhos de Marx, valorizando especialmente o papel do indivíduo e da categoria da alienação. Uma referência importante nesta discussão são as reflexões do estruturalismo introduzidas no debate nos anos 1960, mas pelos limites deste espaço essa análise não será desenvolvida aqui, mesmo porque, como se sabe, a abordagem de Althusser interdita a reflexão sobre questões como a da alienação, por serem consideradas não científicas, filosóficas, características do "jovem Marx". Não obstante, o estruturalismo caracterizou-se principalmente por seu posicionamento anti-humanista, o que o torna um interlocutor oculto sempre que se trata dos temas negados por ele. Os textos de Otto Kallscheuer e Perry Anderson, citados neste artigo, são algumas das referências acerca da presença do estruturalismo no marxismo francês na segunda metade do século XX. Balibar (1996), prefaciando uma nova edição de Pour Marx, faz uma breve caracterização

\begin{tabular}{l|l}
\hline 78 & Algumas reflexões acerca da categoria da alienação no marxismo francês...
\end{tabular}
} 
ação revolucionária em qualquer lugar do globo aos interesses do Estado soviético" (CLAUDIN, 1986, p. 403). Essa posição orientava também o horizonte teórico da esquerda francesa no período que, como mostra Kallscheuer $(1989$, p. 51), era caracterizado por uma dupla filiação: 1) "no materialismo dos enciclopedistas e dos pensadores da tradição cartesiana" (que consideravam com apreço particular as ciências naturais) e 2) no marxismo "soviético".

Para Kallscheuer (1989, p. 51), este marxismo do PCF, "ancorado politicamente à União Soviética e teoricamente ao materialismo das ciências naturais, não era culturalmente capaz de sobreviver à guerra fria". O autor faz uma só ressalva: Henri Lefebvre seria, para ele, "talvez a única exceção", pois "tinha publicado já nos anos 1930 as primeiras traduções dos Manuscritos econômico-filosóficos, de Marx, e dos Cadernos filosóficos de Lênin. A ele devemos, de 1950" (KALLSCHEUER, 1989, p. 52), afirma.

Assim, quando em 1956 o chamado "socialismo realmente existente" se vê abalado pela reação desencadeada pelas declarações de Kruschev no $\mathrm{XX}^{\mathrm{o}}$ congresso do PCUS e o marxismo "soviético" passa a ser abertamente questionado, Lefebvre mantém sua linha de reflexão, reforçada pelo rumo dos acontecimentos. Logo, o "repensar Marx" - provocado pela crise de 1956 - teve como uma de suas conseqüências o retorno aos textos "juvenis" que, como vimos, já faziam parte do universo de pesquisa de Lefebvre desde os anos 1930.

Na primeira parte de Crítica da vida cotidiana, Lefebvre retoma alguns elementos do trabalho de 1936, ampliando a crítica às tendências irracionalistas que se desenvolveram no período da segunda guerra. Diante da arte e da filosofia que traduzem essas tendências, afirma a necessidade de reabilitar a vida cotidiana, visto que nos poetas e metafísicos ditos "modernos" pode-se encontrar "os elementos de uma certa crítica da vida cotidiana, mas indireta e sempre fundada sobre a confusão entre o real humano e o real capitalista". Para ele a "verdadeira crítica da vida cotidiana, que terá por primeiro objetivo a separação entre o humano (real e possível) e a decadência burguesa, implicará uma reabilitação da vida cotidiana". Pergunta-se, pois:

(...) não é na vida cotidiana que o homem deve realizar sua vida humana? A teoria dos momentos sobre-humanos é inumana. Não é na vida de cada dia (...) que é preciso dominar a verdade na alma e no corpo? Se a vida superior, aquela do "espírito", deve ser

\footnotetext{
do período de forma sintética.
}

cadernos cemarx, $\mathrm{n}^{\mathrm{O}} 5-2009 \quad 79$ 
realizada em uma "outra vida" - além-mundo místico e mágico - seria o fim do homem. A proclamação de sua falência. O homem será cotidianamente ou não será (LEFEBVRE, 1958, p. 140).

Para o autor, o marxismo é a descrição e a análise da vida cotidiana e da sociedade e "indica os meios de transformá-la" (LEFEBVRE, 1958, p. 161). E mais:

não se contenta em descobrir e criticar essa vida real, prática, no detalhe da sociedade. Ele sabe passar para uma integração racional de um indivíduo ao social - do nível individual ao nível nacional e social. E inversamente (Lefebvre, 1958: 161).

Como Lefebvre considera que a "penetração da vida individual e cotidiana do método dialético é bastante pouco conhecida" (LEFEBVRE, 1958, p. 161), resgata alguns elementos do marxismo que dizem respeito a essa crítica. O primeiro deles é a crítica da individualidade, na qual identifica como tema central a consciência "privada", descrevendo-a do seguinte modo:

(...) os indivíduos no mundo da produção são efetivamente conscientes de si, mas eles tendem a viver dobrados sobre si mesmos, sobre sua técnica e sua especialização. O resto da vida social e humana, eles não são conscientes senão para rejeitar, desdenhar, ou se transpor no irreal. Eles tendem ao individualismo. Ora, se a individualidade humana deve consistir em uma certa relação do ser singular com o universal - razão, sociedade, cultura, mundo - não se trata aqui da verdadeira individualidade, mas somente de uma forma abstrata, vide, negativa, do individual. É esta forma, com um mínimo de conteúdo, que se pode nomear "consciência privada". Ela é consciência de si, mas consciência limitada, demarcada, negativa, formal. Esta consciência, separada de suas condições de (...) existência, crê que ela se basta e tenta se bastar. Ela degenera. E é isso que exprime perfeitamente a expressão correntemente empregada para designar a vida cotidiana dos indivíduos nesta estrutura social: a vida privada. É certamente uma vida "privada": privada de realidade, de ligação com o mundo - uma vida em que todo o humano é estranho - aquela do indivíduo conformado pelas tendências individualistas (LEFEBVRE, 1958, p. 161).

Os outros elementos levantados pelo autor são: crítica das mistificações (tema central: a consciência "mistificada"), crítica do dinheiro (tema central: o fetichismo e a alienação econômica), crítica das necessidades (tema central: a alienação psicológica

80 Algumas reflexões acerca da categoria da alienação no marxismo francês... 
e moral), crítica do trabalho (tema central: alienação do trabalhador e do homem) e crítica da liberdade (tema central: o poder do homem sobre a natureza e sobre sua própria natureza). Enfim, Lefebvre constrói esse diálogo com a literatura e a filosofia do seu tempo, resgatando da análise marxista aqueles temas que mais nitidamente contribuem para alcançar seu objetivo colocado inicialmente - o de proceder a separação entre "o humano (real e possível) e a decadência burguesa".

No prefácio de 1958, Lefebvre atualiza o exame de obras que apareceram nos anos entre a primeira e a segunda publicação do livro. Além disso, dedica-se às mudanças sociais ocorridas nesse intervalo (com destaque para o trabalho e lazer) e retoma a análise da alienação em Marx, principalmente nos Manuscritos de 44, questionando a "tendência de cortar Marx de suas raízes, e as obras científicas de sua maturidade das obras de juventude" (LEFEBVRE, 1958, p. 63).

Muitos outros trabalhos de Lefebvre mereceriam ser recuperados. A própria Crítica da vida cotidiana ganha mais outros dois volumes, além de Vida cotidiana no mundo moderno, de 1968. A sua discussão sobre a cidade certamente também ofereceria elementos importantes para análise da alienação. Mas, pelos limites deste artigo somente mais um texto de Lefebvre será ainda lembrado. Trata-se de Metafilosofia (1967), no qual, ao mesmo tempo em que retoma a crítica de Marx a Hegel para tratar da superação da filosofia, realiza um acerto de contas com o marxismo oficial. Segundo ele, a "crítica radical da filosofia, que traz sua verdade social e prática, liga-se a crítica do estado. O estado deve perecer para que a filosofia se realize e sejam atingidos na práxis seus objetivos" (LEFEBVRE, 1967, p. 78). Portanto:

Se a revolução proletária não segue o curso anunciado por Marx, se o proletariado se mostra incapaz de cumprir sua missão histórica, então o estado não perece; continua. A filosofia continua igualmente, mas se aplica seja a uma crítica pouco eficaz, seja à apologia do estado existente (...) Correrá o risco de tornar-se empírica, pragmática, instrumental: ideologia posta a serviço da política, dogmatismo constituindo o saber abstrato próprio de uma burocracia política, critério de seleção dos quadros institucionais, justificação do estado e de seu aparelho. Só uma ligação com o estado e a burocracia assegurará à filosofia certa eficácia e ao filósofo as honras públicas (LEFEBVRE, 1967, p. 79).

É evidente que não se trata somente de uma análise teórico-conceitual, mas da denúncia de uma situação que o envolveu diretamente.

cadernos cemarx, $\mathrm{n}^{0} 5-2009 \quad 81$ 
É também em tom de denúncia que André Gorz (1992) abre seu livro La morale de l'histoire $^{4}$, citando o ataque do governo socialista ao Egito, em 1956, "para perpetuar um regime colonialista na Argélia"s e o apoio do PCF ao massacre na Hungria, promovido pelo exército soviético naquele mesmo ano. Nesse trabalho, Gorz coloca em questão o papel das escolhas individuais no processo de construção de uma sociedade alternativa à capitalista. Diante das justificativas para o ataque do governo socialista da França ao Egito e ao apoio do PCF à repressão na Hungria, desabafa:

Agora compreendo meu mal-estar e minha rebeldia frente a esses marxistas que pretendem explicar-me a necessidade da política staliniana ou krucheviana pela inevitabilidade dos imperativos materiais. Se tiverem razão, se o comunismo não é senão um processo determinado, que arrasta aos dirigentes impelindo-lhes seu sentido, perde, com efeito, sua finalidade humana, não é melhor que o capitalismo, não há uma diferença profunda entre o comitê central do PCUS e o conselho de ministros de Mollet. (GORZ, 1992, p. 23).

Não é o caso de nos determos na especificidade da questão colocada por Gorz, mas somente identificar o debate que se instalou entre os comunistas franceses a partir dos acontecimentos da época. $\mathrm{O}$ autor argumenta a favor da crítica, afirmando que:

(...) justamente porque a empresa comunista tem como fim fazer o homem, vale a pena criticá-la: porque seus fins são fins humanos, os homens podem opinar acerca da direção que toma, podem reivindicar o controle constante do desenvolvimento; sua crítica é indispensável se o empreendimento quer conservar seu sentido humano: sua crítica é eficaz porque a empresa comunista não está predeterminada, senão que é obra dos homens que perseguem seus fins próprios (GORZ, 1992, p. 24).

Acrescenta que em relação às sociedades capitalistas as exigências são

4 Na edição mexicana o título foi traduzido por Historia e enajenación. A publicação original é de 1959

5 Recentemente, a imprensa britânica divulgou o conteúdo de alguns documentos dos arquivos nacionais britânicos segundo os quais o então primeiro ministro francês Guy Mollet solicita a admissão da França na comunidade britânica das nações (Commonwealth of Nations). "Segundo a fonte, Mollet se sentia pressionado pela crise do canal de Suez e pelos combatentes da Argélia, que estavam sendo financiados pelo presidente do Egito, Gabel Abdel Nasser". In: Documento eletrônico.<http://ultimosegundo.ig.com.br/mundo/2007/01/15/documento_diz_que_franca_propos_uniao_com_gra_ bretanha_em_1956_351066.html>. Acesso em 04/03/2007.

\begin{tabular}{l|l}
\hline 82 & Algumas reflexões acerca da categoria da alienação no marxismo francês...
\end{tabular} 
menores, visto que "são arrastadas por processos que não controlam (e que não podem, nem podem querer, controlar)" (GORZ, 1992, p. 24). Na segunda parte de seu texto, Gorz trata da elaboração de uma teoria da alienação. Retoma, então, a tematização de Marx, em especial nos Manuscritos de 44, mas não perde de vista o objetivo de analisar o papel das decisões individuais nos processos históricos. Neste sentido, constrói a seguinte reflexão:

Minha situação singular é sempre a especificação de uma situação que me envolve; meus fins pessoais são sempre especificações de fins mais gerais (...) a razão última da alienação mútua dos indivíduos deve buscar-se na alienação de cada indivíduo com respeito às exigências materiais do campo prático (GORZ, 1992, p. 78-79).

Colocado dessa forma, diz o autor adiante, parece que os indivíduos são um produto da sociedade "que se serve deles com vistas a seus fins" (GORZ, 1992, p. 97). E, após uma longa citação de A ideologia alemã, afirma que em "realidade, os indivíduos são os produtores de sua própria condição e do processo socioeconômico" (Gorz, 1992: 98). Esta realidade está oculta aos indivíduos, segundo Gorz, em primeiro lugar porque "a sociedade não era o fim das atividades individuais" (GORZ, 1992, p. 98). Para o autor:

A originalidade do marxismo é que ele não se reduz a uma teoria científica dos processos socioeconômicos. Esses processos, pelo contrário, assim como suas leis, não lhe interessam enquanto são explicações rigorosas do "curso de mundo"; interessamlhe, sobretudo, enquanto permitem compreender a contradição que se desenvolve "inexoravelmente" entre os fins dos indivíduos e os resultados que produzem (GORZ, 1992, p. 110).

Desse modo, Gorz coloca no centro do debate a contradição entre indivíduo e sociedade nos termos da reflexão marxiana da categoria da alienação. Neste sentido, afirma:

Em nenhum caso pode admitir-se que a mudança histórica seja o fruto de uma evolução mecânica. Resulta, pelo contrário, da conversão dos fins humanos, conversão operada quando os indivíduos reconhecem a resultante de seus atos como um obstáculo insuperável para a realização de seus fins primários (GORZ, 1992, p. 111).

Tratando do que seriam os referidos "fins primários", Gorz desenvolve,

cadernos cemarx, $\mathrm{n}^{\mathrm{o}} 5-2009 \quad 83$ 
no capítulo seguinte, uma análise acerca da "alienação das necessidades". Aqui, retoma a crítica de Marx, nos Manuscritos, ao comunismo grosseiro e seu desejo de nivelação, ou seja, à perspectiva de "generalizar a pobreza" (GORZ, 1992, p. 270), desconsiderando, desse modo, a riqueza das faculdades humanas que se desenvolve no contato com os objetos sociais e com os outros homens. Sem citar Marx diretamente, ele assume o debate da Introdução de 57 ao esclarecer como a indústria orienta a produção de necessidades. Constrói, então, uma reflexão sobre a produção do indivíduo na sociedade capitalista, tratando da formação da personalidade individual, tema que, como veremos adiante, será central nos estudos de Lucien Sève.

Na conclusão de seu trabalho de 1959, Gorz retorna à análise das possibilidades do socialismo, afirmando que ele "não resolve todos os problemas humanos" (GORZ, 1992, p. 318) e, no caso das "sociedades socialistas atuais", dominadas pela escassez e pela necessidade, não se pode exigir uma resposta sem que se eliminem as causas dos problemas materiais. Arrematando sua reflexão, o autor situa mais perguntas do que respostas ${ }^{6}$, o que o leva a se adiantar em relação às possíveis críticas: "Miserável dirão talvez vocês -; escreve todo um livro para demonstrar o valor ético da exigência marxista e fundar nela sua tomada de posição em favor do socialismo, para dizer-nos finalmente que não sabe se o comunismo fará felizes aos homens e suprimirá todas as alienações". Quanto a essas possíveis objeções, o autor responde que ele acredita que "essa maneira teológica de apresentar o socialismo faz mais mal do que bem", pois enquanto empreendimento humano, ele tem valor não somente no resultado, mas na "própria ação de fazê-lo, enquanto confirmará a exigência do homem de colocar-se como fundamento da sociedade" (GORZ, 1992, p. 321). A respeito da apropriação do mundo e da história, diz ele:

(...) será necessariamente uma empresa infinita. Não podemos saber como nem em que medida será alcançada e podemos adivinhar que jamais se realizará plenamente. Esta não é uma razão para não desejá-la, para não apoiar a única classe que, por sua práxis, pode empreendê-la. Para nós não há outra esperança possível, nem condição mais desesperante do que permanecer atracados em nossas alienações presentes por medo de que sua superação engendre outras alienações.

\footnotetext{
6 "Não sei quando nem como as sociedades socialistas atuais passarão a essa 'fase superior da sociedade comunista... onde as fontes da riqueza coletiva surgirão com abundância'; não sei se as condições demográficas e geológicas permitirão a abundancia universal; e não sei tampouco que outras alienações resultarão da sociedade comunista; nem sequer sei se os homens serão felizes nela" (GORZ, 1992, p. 320).

\begin{tabular}{l|l}
\hline 84 & Algumas reflexões acerca da categoria da alienação no marxismo francês...
\end{tabular}
} 
Alguns anos depois, em 1966, a partir de uma série de conferências proferidas na Escola Nacional de Ciências Políticas e Sociais do México, Gorz (1968) amplia o debate acerca da alienação, discutindo também outros temas em pauta ${ }^{7}$, mas sobre os quais não nos dedicaremos neste trabalho.

Em 1974, Lucien Sève publica Análises Marxistas da Alienação (1975), livro que trata diretamente do tema do presente artigo, mas que já foi objeto de investigação em outros momentos ${ }^{8}$. Será considerado um ensaio intitulado Marxismo e teoria da personalidade (1972), publicado em 1969, no qual o problema da alienação já aparecia como central. Nessas duas oportunidades, Sève explicita um grande domínio das obras de Marx e um cuidadoso exame da categoria da alienação em períodos distintos do itinerário marxiano.

No texto de 1969, o autor afirma de partida que o "presente livro é totalmente o contrário de uma obra circunstancial, fruto da improvisação" (SÈVE, 1972, p. 07). E nos fala da motivação, desde o período de graduação em filosofia, quando no contato com a psicologia existente só encontrou "rigor cientifico no estudo de objetos completamente impessoais, sem divisar nela nada que mostrasse uma relação concreta com os problemas de uma vida humana real" (SÈVE, 1972, p. 07). A crítica da psicologia de Politzer, os estudos de Lênin nos anos 50 e principalmente "a leitura e o estudo atento de O capital" (SÈVE, 1972, p. 08), realizado em 1953, são referências construídas por muito tempo por Sève para o seu Marxismo e teoria da personalidade.

Sève, portanto, insere-se no debate de seu tempo a partir da preocupação com a formação da personalidade individual. Afirma ele:

(...) a importância verdadeiramente central do problema da individualidade humana se manifestava em todos os pontos cardeais da investigação marxista e dos debates ideológicos: crítica e superação das deformações dogmáticas do marxismo, assim como de sua alteração "humanista"; elaboração precisa do materialismo histórico e reflexão acerca das modalidades e finalidades humanas do socialismo; discussão dos resultados recentes das ciências do homem e do anti-humanismo estruturalista; tudo isso traz de contínuo à ordem do dia a pergunta temível: que é o homem? (SÈVE, 1972, p. 09).

7 Dentre outros, discute o problema do colonialismo, o debate sino-soviético e a questão do Vietnã. $8 \mathrm{Na}$ introdução da minha dissertação de mestrado, tratei rapidamente da abordagem de Seve; em um artigo, produzido para a seleção de doutorado, ela também foi objeto de pesquisa. 
Foi precisamente essa temível pergunta que levou Sève a buscar nos textos de Marx elementos para análise. O autor considera a teoria da alienação dos Manuscritos como pré-marxista (SÈVE, 1972, p. 66). Por isso mesmo, irá considerar o problema a partir de A ideologia Alemã, pois, para ele, em 1845-46 se deu a mais decisiva entre as rupturas no avanço científico do pensamento de Marx'.

No capítulo em que trata da articulação, entre psicologia da personalidade com o Marxismo, Sève imediatamente afirma que há

(...) entre as forças produtivas e os homens uma correspondência fundamental: a de que eles são, precisamente, a força produtiva mais importante. Considerados antes de tudo em sua condição de produtores, de forças de trabalho, ou seja, de um "conjunto de faculdades físicas e intelectuais que existem no corpo de um homem, em sua personalidade viva" (SÈVE, 1972, p. 134).

O trecho final é extraído de O Capital, sobre cuja leitura o autor se pergunta:

(...) como é possível ler em $O$ capital, por exemplo, as páginas dedicadas à distinção entre trabalho concreto e abstrato, o valor da força de trabalho e a taxa do salário, a divisão do trabalho e a manufatura capitalista, o efeito do dinheiro nas relações mercantis, a extorsão da mais-valia absoluta e relativa, a lei geral da acumulação capitalista etc. até as últimas páginas dedicadas às classes sociais, sem compreender que se trata de indivíduos humanos para além de categorias econômicas (SÈVE, 1972, p. 136).

Arrisca uma resposta para essa interrogação, tomando-a em "seu nível mais simples" (SÈVE, 1972, p. 136), ou seja, para compreender essa articulação entre a análise econômica de Marx e a ciência do indivíduo "há de estar em condições de conceber (...) a idéia radicalmente nova de que uma ciência semelhante seja articulável com a economia política e o materialismo histórico de Marx" (SÈVE, 1972, p. 136). Para ele, a ignorância em relação a essa possibilidade na obra de Marx está relacionada à compreensão de que qualquer teoria da personalidade é especulativa.

Oesforço de Sève para empreender a elaboração de uma teoria da personalidade não especulativa chega ao ponto de buscar, a partir de O Capital, referências para

\footnotetext{
9 Sève afirma que "não seria demasiado dizer que desde os Manuscritos de 1844 até as obras marxistas da maturidade há avanço científico; este foi marcado por uma ruptura - melhor dito, rupturas - de continuidade, a mais decisiva das quais se produziu em 1845-46" (SĖVE, 1972, p. 69).

86

Algumas reflexões acerca da categoria da alienação no marxismo francês...
} 
determinar o papel do emprego do tempo na formação da personalidade. Com efeito, o que há de mais objetivo quando se trata da formação dos sentidos e, portanto, da personalidade, do que o uso efetivo da matéria através da qual nos formamos como seres humanos?

Em síntese, o marxismo francês do período pós-guerra (Lefebvre) até os anos 1960 (Lefebvre, Gorz, Sève e outros) trouxe para a discussão a questão central da produção do indivíduo na vida social em um fértil debate entre as referências analíticas de Marx e as questões concretas do socialismo realmente existente. Mas, paralelamente - para ser preciso, a partir de $1965^{10}$ - produziu um afastamento tal do homem a ponto de desembocar em uma estrutura sem sujeito - para usar os termos de Anderson (1985) em A crise da crise do marxismo.

Assim, de um cenário analítico marcado pela aproximação ao indivíduo concreto produzido historicamente (Gorz, Sève e Lefebvre e, claro, muitos outros ${ }^{11}$ ) chega-se àquilo que Chasin caracterizou como "absurdo ontológico", aquela situação na qual, pelo distanciamento da vida real prática, "parte-se de imediato da teoria e não do ser que faz a teoria, ou [parte-se] deste como uma abstração da inteligibilidade, ou seja, de uma faculdade abstraída do ser que a possui" (CHASIN, apud VAISMAN, 2001, XI). O "absurdo ontológico" é a suposição de que há uma teoria acima dos homens, que caracteriza, de forma distinta, desde os grandes sistemas filosóficos até o estruturalismo francês.

Portanto, retomar a análise dos autores tratados nesta pequena pesquisa, e de outros que investiram na apropriação reflexiva das possibilidades humanas, significa reacender o debate acerca da transformação social sem desconsiderar o papel dos indivíduos sociais nesse processo.

\section{Bibliografia}

ANDERSON, Perry. A crise da crise do marxismo. São Paulo: Brasiliense, 1985.

BALIBAR, Étienne. "Avant-propos". In: Althusser, L. Pour Marx. Paris: La Découverte, 1996.

10 Ano de publicação de Lire le Capital e Pour Marx de Althusser.

11 Muitos outros autores, não mencionados no presente artigo, dentro e fora da França, se ocuparam da análise da categoria da alienação. A relação entre indivíduo e sociedade é, por exemplo, um tema central do último ensaio escrito por Lukács (1990) antes de sua morte, os Prolegômenos à ontologia do ser social (ainda não publicado no Brasil). O plano de trabalho para o estágio de pós-doutorado da professora Ester Vaisman discute exatamente as relações entre indivíduo e gênero nos Prolegômenos. Portanto, "promover" uma interlocução desses autores com aqueles do marxismo francês aqui analisados pode se constituir um trabalho fecundo para pesquisas futuras.

cadernos cemarx, $\mathrm{n}^{\mathrm{O}} 5-2009 \quad 87$ 
CLAUDÍN, Fernando. A Crise do movimento comunista. 2. O apogeu do stalinismo. São Paulo: Global, 1986.

GORZ, André. O socialismo difícil. Rio de Janeiro: Zahar Editores, 1968.

Historia e enajenación. México: Fondo de cultura econômica, 1992.

KALLSCHEUER, Otto. "Marxismo e teoria do conhecimento". In: HOBSBAWM, Eric (org.). Marxismo Hoje. Rio de Janeiro: Paz e Terra, 1989.

LEFEBVRE, Henri. Crítique de la vie quotidienne. 1 - Introduction. Paris: L'Arche Éditeur, 1958.

Metafilosofia. Rio de Janeiro: Martins Fontes, 1967.

Tiempos equivocos. Barcelona: editorial Kairós, 1975.

LUKÁCS, György. Prolegomeni all'ontologia dell'essere sociale. Questioni di principio di um'ontologia oggi divenuta possibile. Milão: Guerini e Associati, 1990.

SÈVE, Lucien. Marxismo y teoria de la personalidad. Buenos Aires: Amorrortu Editores, 1972.

Análises Marxistas da Alienação. Lisboa: Edições Mandacaru,

VAISMAN, Ester. "Dossiê Marx: itinerário de um grupo de pesquisa". In: Revista

Ensaios Ad Hominem 1 - tomo IV. São Paulo: Estudos e Publicações Ad Hominem,

2001.

88 Algumas reflexões acerca da categoria da alienação no marxismo francês... 